\begin{tabular}{|c|l|}
\hline Title & Synthesis and Photocrosslinking Reaction of N-A lly Icarbamoy Imethyl Cellulose Leading to Hydrogel \\
\hline Author(s) & $\begin{array}{l}\text { Shen, Xiande; Kitajyo, Y oshikazu; Duan, Qian; Narumi, A tsushi; Kaga, Harumi; Kaneko, Noriaki; Satoh, Toshifumi; } \\
\text { Kakuchi, Toyoji }\end{array}$ \\
\hline Citation & $\begin{array}{l}\text { Polymer Bulletin, 56(2-3), 137-143 } \\
\text { https://doi.org/10.1007/300289-005-0482-2 }\end{array}$ \\
\hline Issue Date & 2006 \\
\hline Doc URL & http://hdl.handle.net/2115/5737 \\
\hline Rights & The original publication is avail lable at www.springerlink.com \\
\hline Type & article (author version) \\
\hline File Information & PB56(2-3).pdf \\
\hline
\end{tabular}

Instructions for use 


\title{
Synthesis and Photocrosslinking Reaction of $N$-Allylcarbamoylmethyl Cellulose Leading to Hydrogel
}

\author{
Xiande Shen, ${ }^{1}$ Yoshikazu Kitajyo, ${ }^{1}$ Qian Duan, ${ }^{1}$ Atsushi Narumi, ${ }^{2}$ Harumi Kaga, ${ }^{2}$ \\ Noriaki Kaneko, ${ }^{3}$ Toshifumi Satoh, ${ }^{1}$ and Toyoji Kakuchi ${ }^{1}$ (()) \\ ${ }^{1}$ Division of Biotechnology and Macromolecular Chemistry, Graduate School of Engineering, \\ Hokkaido University, Sapporo 060-8628, Japan \\ ${ }^{2}$ National Institute of Advanced Industrial Science and Technology (AIST), Sapporo 062-8517, \\ Japan \\ ${ }^{3}$ MACROTEC Co., Sapporo 062-8517, Japan \\ E-mail: kakuchi@poly-mc.eng.hokudai.ac.jp FAX:+81-11-706-6602
}

\section{Summary}

The reaction of the carboxymethyl cellulose sodium salt (Na-CMC) (degrees of substitution $(\mathrm{DS})=1.2$ ) with $N$-hydroxysuccinimide $(\mathrm{Su}-\mathrm{OH})$ in the presence of 1hydroxybenzotriazole and 1-ethyl-3-(3-dimethylaminopropyl)carbodiimide (EDC) was carried out in water to obtain the Su-OH ester of carboxymethyl cellulose, SuCMC, with the DS values of $0.19-1.04$. N-Allylcarbamoylmethyl cellulose (Allyl$\mathrm{CMC}$ ), which was prepared from the reaction of Su-CMC with an excess amount of allylamine, was crosslinked by UV-irradiation. In addition, the photocrosslinked Allyl-CMC film was swollen with water to form a hydrogel having a relatively high water-swelling property, e.g., the degree of swelling (ds) was ca. $360 \%$ for AllylCMC with the DS of 0.93 .

\section{Introduction}

Cellulose, one of the biorenewable polymers with biodegradable and biocompatible properties, is an inexpensive commercial product. Thus, of great interest is the application of cellulose as a precursor for chemical modification leading to various types of cellulose derivatives, such as the nitrate [1], ester [2-4], ether [5-7], and carbamate [8-9] of cellulose. In addition, carboxymethyl cellulose (CMC), the most important ionic cellulose ester, is widely used as building material additives, printing inks, coatings, pharmaceuticals, food, cosmetics, paper or textiles [10-11]. With regard to the biocompatibility of cellulose, CMC should be a key raw material due to the relatively high reactivity of the carboxylic acid group in the CMC. For example, Barbucci et al. reported that CMC was chemically crosslinked with a diaminoalkane to afford hydrogels as a matrix for the realization of controlled drug release systems [12]. Thus, it is important to expand the family of CMC-based hydrogels from the viewpoint of the development of novel biomedical materials [13-14]. 
In this study, we report the synthesis of $N$-allylcarbamoylmethyl cellulose (AllylCMC) through an activated ester method using $N$-hydroxysuccinimide (Su-OH), as shown in Scheme 1. The cast films of the Allyl-CMCs possessing different degrees of substitution (DS) for the $N$-allylcarbamoylmethyl group are irradiated by UV-light to afford water-insoluble crosslinked polymers. In addition, we discuss the effect of the DS and crosslinking degree on the water-swelling property for the photocrosslinked Allyl-CMC hydrogel.

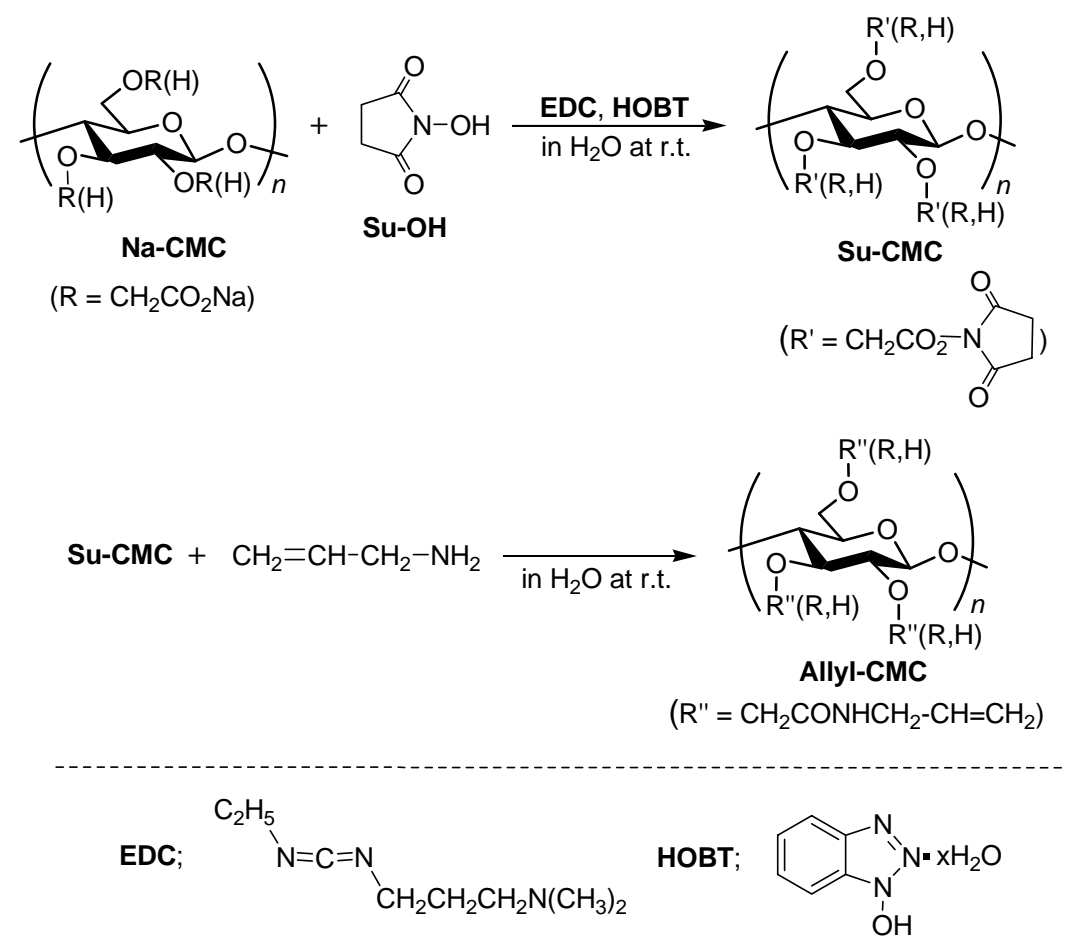

Scheme 1. Synthesis of $N$-allylcarbamoylmethyl cellulose (Allyl-CMC)

\section{Experimental}

\section{Materials}

The carboxymethyl cellulose sodium salt $\left(M_{\mathrm{w}}=250,000\right.$, degree of substitution $\left.=1.2\right)$, 1-hydroxybenzotriazole (HOBT), and sulfuric acid- $d_{2}$ solution $\left(\mathrm{D}_{2} \mathrm{SO}_{4} / \mathrm{D}_{2} \mathrm{O}\right)$ were purchased from Aldrich. $N$-Hydroxysuccinimide (Su-OH), 1-ethyl-3-(3dimethylaminopropyl)carbodiimide (EDC), and allylamine were purchased from Merck, the Peptide Institute, Inc. (Japan), and the Kanto Chemical Co. (Japan), respectively. Seamless cellulose tubing (UC36-32-100) was obtained from the Viskase Companies, Inc. 


\section{Measurements}

The IR spectra were recorded using a Perkin-Elmer Paragon 1000 FT-IR instrument. The ${ }^{1} \mathrm{H}$ NMR spectra of the crosslinked samples in $\mathrm{D}_{2} \mathrm{O}$ containing $\mathrm{D}_{2} \mathrm{SO}_{4}$ were recorded using a JNM-A400II instrument. $p$-Toluenesulfonic acid was used as the internal standard.

\section{Synthesis of N-hydroxysuccinimide ester of carboxymethyl cellulose (Su-CMC)}

A typical procedure is described as follows. A mixture of Na-CMC (2.64 g, $10 \mathrm{mmol})$ in distilled water $(100 \mathrm{ml})$ was stirred for $6 \mathrm{~h}$ at room temperature in order to obtain a homogeneous solution, and then HOBT (1.62 g, 12 mmol), Su-OH (1.38 g, $12 \mathrm{mmol})$, and EDC (1.38 g, $12 \mathrm{mmol})$ were added. After stirring for $6 \mathrm{~h}$ at room temperature, the mixture was transferred to a cellulose tube and dialyzed for 2 days with distilled water. The aqueous solution was freeze-dried to yield a white powder. The elemental analysis data are listed in Table 1 . The degree of substitution for the $\mathrm{N}$ hydroxysuccinimide ester group in the obtained polymer was 1.04.

\section{Synthesis of N-allylcarbamoylmethyl cellulose (Allyl-CMC)}

A typical procedure is described as follows. After a solution of Su-CMC (678 mg, 2 $\mathrm{mmol})$ and allylamine $(228 \mathrm{mg}, 4 \mathrm{mmol})$ in distilled water $(10 \mathrm{ml})$ was stirred for $24 \mathrm{~h}$ at room temperature, the mixture was transferred to a cellulose tube and dialyzed for 2 days with distilled water. The aqueous solution was freeze-dried to yield a white powder. The elemental analysis data are listed in Table 2. The degree of substitution for the $N$-allylcarbamoylmethyl group in the obtained polymer was 0.93 .

\section{UV-irradiation of Allyl-CMC film}

A solution of Allyl-CMC (0.25 g) in a phosphoric acid solution ( $\mathrm{pH}=7.4,5 \mathrm{ml})$ was cast on a glass plate under dark conditions to produce an Allyl-CMC film with a thickness of 1.25-1.5 mm. The film samples were placed on a plastics plank and exposed to $600 \mathrm{~mJ}$ of UV light (254 nm) at a 5-cm distance using a model R-52G UVlamp (UVP, Inc., U.S.A.). After an appropriate irradiation time, the film was soaked in water for $24 \mathrm{~h}$. The mixture was filtered off using a glass filter and then the waterinsoluble polymer was dried in a vacuum. The residual amount of the $\mathrm{N}$ allylcarbamoylmethyl unit in the photocrosslinked Allyl-CMC was determined from the ${ }^{1} \mathrm{H}$ NMR spectrum of the gel in $\mathrm{D}_{2} \mathrm{O} / \mathrm{D}_{2} \mathrm{SO}_{4}$.

\section{Swelling measurements}

The degree of swelling (ds) was calculated using the formula:

$$
\mathrm{ds}=\left(\left(W_{\mathrm{s}}-W_{\mathrm{d}}\right) / W_{\mathrm{d}}\right) \times 100,
$$

where $W_{\mathrm{s}}$ and $W_{\mathrm{d}}$ are the weights of the swollen and dried gels, respectively. The dry state was obtained by lyophilization of the photocrosslinked polymer. In practice, the established amounts $\left(W_{\mathrm{d}}\right)$ of the cross-linked water-insoluble dry polymers were enclosed in small bags made of a hydrophobic water-permeable net (Nylon) and 
immersed for $24 \mathrm{~h}$ at room temperature in $50 \mathrm{ml}$ of distilled water. They were then placed between two pieces of dry filter paper to remove the excess water. The bags containing the swollen films were weighed in order to calculate $W_{\mathrm{s}}$.

\section{Results and discussion}

Scheme 1 outlines the synthesis of the $N$-allylcarbamoylmethyl cellulose (Allyl-CMC) using an activated ester method with $N$-hydroxysuccinimide (Su-OH). First, the carboxymethyl cellulose sodium salt (Na-CMC) was reacted with Su-OH in water using 1-hydroxybenzotriazole (HOBT) and 1-ethyl-3-(3dimethylaminopropyl)carbodiimide (EDC) to quantitatively produce a white powdery product. The absorption at $1730 \mathrm{~cm}^{-1}$ due to the imide carbonyl group was observed in the IR spectrum of the obtained polymer. In addition, the elemental analysis results listed in Table 1 suggested the introduction of the $N$-hydroxysuccinimide unit in the obtained polymer, i.e., the $\mathrm{N}$-hydroxysuccinimide ester of carboxymethyl cellulose (Su-CMC).

The degree of substitution (DS) for the $N$-hydroxysuccinimide ester group could be controlled by varying the molar ratio of Su-OH and the carboxymethyl unit in Na$\mathrm{CMC}$ ([Su-OH]/[- $-\mathrm{CH}_{2} \mathrm{CO}_{2} \mathrm{Na}$ in Na-CMC]); the DS was 0.19, 0.48, and 1.04 for the $[\mathrm{Su}-\mathrm{OH}] /\left[-\mathrm{CH}_{2} \mathrm{CO}_{2} \mathrm{Na}\right.$ in $\left.\mathrm{Na}-\mathrm{CMC}\right]$ of $0.25,0.5$, and 1.0 , respectively.

Table 1. Synthesis of Su-CMC by the reaction between Na-CMC and Su-OH using HOBT and $\mathrm{EDC}^{\text {a) }}$

\begin{tabular}{|c|c|c|c|c|}
\hline$[\mathrm{Su}-\mathrm{OH}]$ & \multicolumn{4}{|c|}{$\mathrm{Su}^{-C M C}{ }^{\text {b) }}$} \\
\hline$\left[-\mathrm{CH}_{2} \mathrm{CO}_{2} \mathrm{Na}\right.$ in $\left.\mathrm{Na}-\mathrm{CMC}\right]$ & $\mathrm{C}$ & $\mathrm{H}$ & $\mathrm{N}$ & DS \\
\hline 0.25 & 41.07 (40.37) & $4.56(4.44)$ & $0.98(0.98)$ & 0.19 \\
\hline 0.5 & $42.08(42.12)$ & $4.68(4.51)$ & $2.26(2.28)$ & 0.48 \\
\hline 1.0 & $44.04(44.86)$ & $4.80(4.61)$ & 4.29 (4.33) & 1.04 \\
\hline
\end{tabular}

a) DS of Na-CMC, 1.2. b) The calculated values are in parentheses.

For the preparation of Allyl-CMC, Su-CMC was reacted with an excess amount of an allylamine. The reaction was carried out in water at room temperature, and the reaction mixture was purified by dialysis in water for 2 days to quantitatively afford a white product. Figure 1a shows the ${ }^{1} \mathrm{H}$ NMR spectrum of the obtained polymer in $\mathrm{D}_{2} \mathrm{O}$. The signals assignable to the allyl group appeared at $5.39-5.44$ and $5.89-5.93$ $\mathrm{ppm}$ and the elemental analysis result of the obtained polymer agreed with the calculated value for the Allyl-CMC, as listed in Table 2. The DS for the $\mathrm{N}$ allylcarbamoylmethyl group in Allyl-CMC was similar to that for the $\mathrm{N}$ hydroxysuccinimide ester group in the precursor polymer, Su-CMC; the DS value for Allyl-CMC was 0.16, 0.48, and 0.93, and for Su-CMC with the DS of 0.19, 0.48, and 1.04, respectively. This means that the activated ester method using $N$ hydroxysuccinimide (Su-OH) is a useful strategy for introducing the appropriate functional group into the CMC. 
Table 2. Elemental analysis and the DS for Allyl-CMC ${ }^{\text {a) }}$

\begin{tabular}{c|cccc}
\hline sample & C & H & N & DS \\
\hline I & $40.14(40.87)$ & $4.97(4.71)$ & $0.83(0.86)$ & 0.16 \\
II & $43.70(44.36)$ & $5.89(5.34)$ & $2.34(2.52)$ & 0.48 \\
III & $48.40(49.04)$ & $6.56(6.18)$ & $4.82(4.75)$ & 0.93 \\
\hline
\end{tabular}

a) The calculated values are in parentheses.

In order to study the photocrosslinking reaction of Allyl-CMC, a dry film was prepared from the casting of the solution of Allyl-CMC in water on a glass plate under dark conditions. The Allyl-CMC film with a thickness of $1.25-1.5 \mathrm{~mm}$ was exposed to an UV light $(254 \mathrm{~nm})$ at a 5 -cm distance for the predicted irradiation time. The water-soluble part was removed from the UV-irradiated film by extracting with water, and the residual photocrosslinked Allyl-CMC was water-insoluble, but soluble in an aqueous solution containing sulfuric acid. Thus, the ${ }^{1} \mathrm{H}$ NMR spectrum of the photocrosslinked Allyl-CMC in $\mathrm{D}_{2} \mathrm{O} / \mathrm{D}_{2} \mathrm{SO}_{4}$ was measured using $p$-toluenesulfonic acid as the internal standard in order to determine the residual amount of the $\mathrm{N}$ allylcarbamoylmethyl unit. The signal intensity for $N$-allylcarbamoylmethyl group decreased for the photocrosslinked Allyl-CMC when compared to that for the film before irradiation (Figure 1b).

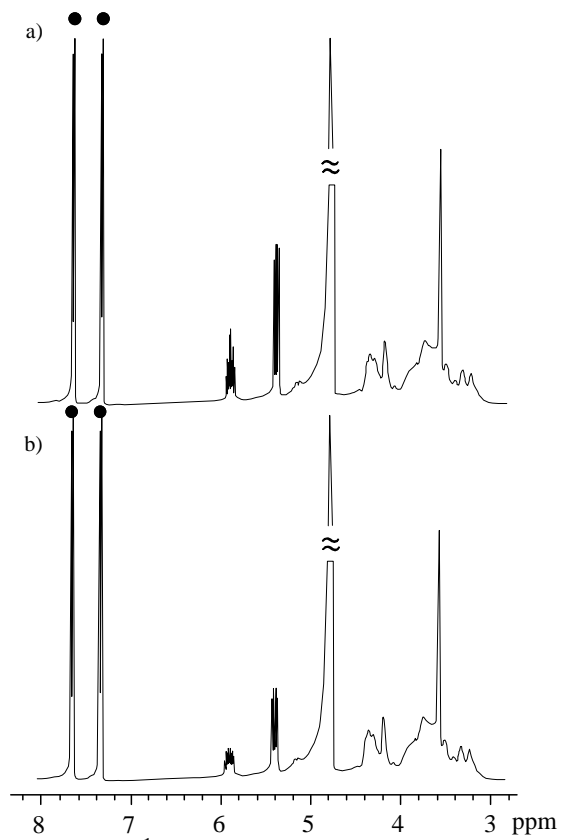

Figure 1. ${ }^{1} \mathrm{H}$ NMR spectra of Allyl-CMC a) before (in $\mathrm{D}_{2} \mathrm{O}$ ) and $\mathrm{b}$ ) after (in $\mathrm{D}_{2} \mathrm{O} / \mathrm{D}_{2} \mathrm{SO}_{4}$ ) $\mathrm{UV}$-irradiation using $p$-toluenesulfonic acid (•) as the internal standard.

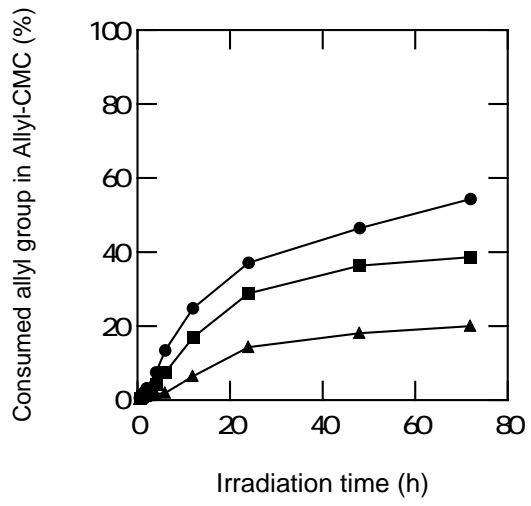

Figure 2. Relationships between the consumed allyl group and irradiation time for the photocrosslinking reaction of the Allyl-CMC with the DS's of 0.16 ( $\mathbf{\Delta}) 0.48$, (ש), and $0.93(\bullet)$.

Figure 2 shows the relationships between the consumed allyl group and irradiation time for the UV-irradiation toward the Allyl-CMC film. The amount of the $\mathrm{N}$ allylcarbamoylmethyl group apparently decreased with the increasing irradiation time. In addition, Figure 2 suggested that the DS of the Allyl-CMC significantly affected 
the degree of crosslinking. As examples, the consumed allyl groups reached 20, 39, and $54 \%$ after 72 hrs for the Allyl-CMCs with the DS's of 0.16, 0.48, and 0.93, respectively. Figure 3 shows the relationships between the yield of the waterinsoluble materials and irradiation time for the photocrosslinked reaction of the AllylCMC. As expected, the yield of the photocrosslinked Allyl-CMC increased with the increasing irradiation time. The yields of the water-insoluble materials reached, for example, 60, 79, and $99 \%$ after 72 hrs for the photocrosslinked reactions of AllylCMCs with the DS's of $0.16,0.48$, and 0.93 , respectively. Thus, the yields also increased with the increasing DS's. It should be noted that the Allyl-CMC with a DS of 0.93 quantitatively provided water-insoluble materials after the irradiation time of $24 \mathrm{~h}$.

The photocrosslinked Allyl-CMC showed the water-uptake property, thus we were able to construct a novel CMC-based hydrogel. Figure 4 shows the relationships between the degree of swelling (ds) estimated by the tea-bag method and irradiation time for the photocrosslinked Allyl-CMCs (see Experimental). Figure 4 indicated that not only the irradiation time, but also the DS significantly affected the water uptake ability. The Allyl-CMC with the DS of 0.93 showed a relatively high waterswelling property with the sd value of ca. $360 \%$.

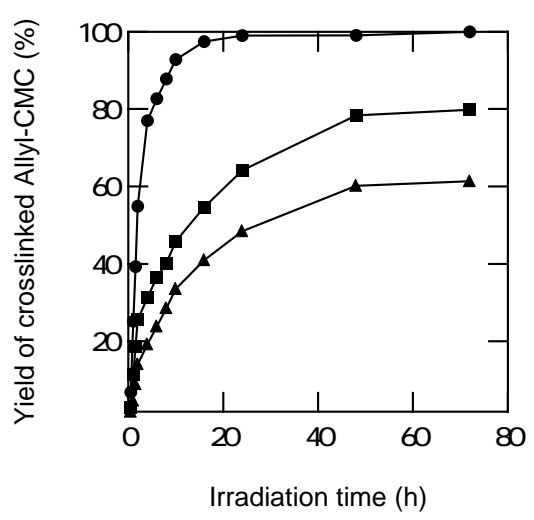

Figure 3. Relationships between the yield of the water-insoluble material and irradiation time for the photocrosslinking reaction of the Allyl-CMCs with the DS's of 0.16 (₫) 0.48 , $(\boldsymbol{\nabla})$, and $0.93(\bullet)$.

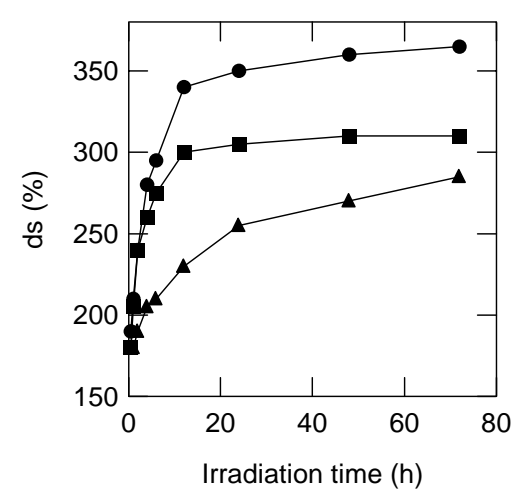

Figure 4. Relationships between the degree of swelling and irradiation time for the photocrosslinked Allyl-CMCs with the DS's of $0.16(\boldsymbol{\Lambda}) 0.48,(\boldsymbol{\square})$, and $0.93(\bullet)$.

\section{Conclusion}

A novel type of CMC-based hydrogel was synthesized by the photocrosslinking reaction of $N$-allylcarbamoylmethyl cellulose (Allyl-CMC). For the synthesis of the Allyl-CMC, the activated carboxylate method using $N$-hydroxysuccinimide was efficient for introducing the allyl group into the CMC. In addition, the photocrosslinked Allyl-CMC exhibited a water-uptake property, which is expected to be a novel material for biomedical applications. 


\section{References}

1. Wagenknecht W, Nehls I, Philipp B (1992) Carbohydr Res 237:211.

2. Edgar KJ, Buchanan CM, Debenham JS, Rundquist PA, Seiler BD, Shelton MC, Tindall D (2001) Prog Polym Sci 26:1605.

3. McCormick CL, Dawsey TR (1990) Macromolecules 23:3606.

4. McCormick CL, Callais PA (1987) Polymer 28:2317.

5. Isogai A, Ishizu A, Nakano J, Eda S, Kato K (1985) Carbohydr Res 138:99.

6. Isogai A, Ishizu A, Nakano J (1986) J Appl Polym Sci 31:341.

7. Isogai A, Ishizu A, Nakano J (1984) J Appl Polym Sci 29:2097.

8. Mornann W, Michel U (2002) Carbohydr Polym 50:201.

9. Hearon WM, Hiatt GD, Fordyce CR (1943) J Am Chem Soc 65:829.

10. Heinze T, Liebert T (2001) Prog Polym Sci 26:1689.

11. Olaru N, Olaru L, Stoleriu A, Timpu D (1998) J Appl Polym Sci 67:481.

12. Barbucci R, Leone G, Vecchiullo A (2004) J Biomater Sci Polymer Edn 15:607.

13. Carrigan SD, Scott G, Tabrizian M (2005) Langmuir 21:5966.

14. Hara K, Iida M, Yano K, Nishida T (2004) Colloid Surf B: Biointerfaces 38:227. 